\title{
Genetic neighbourhood sizes in Primula vulgaris
}

\author{
C. M. Cahalan* and C. Gliddon
}

School of Plant Biology, University College of North Wales, Bangor, Gwynedd

\begin{abstract}
Neighbourhoods in natural populations of Primula vulgaris were found to be small, with neighbourhood sizes ranging from 1 to 38 plants and neighbourhood areas varying with the density of populations betweell $0 \cdot 30 \mathrm{~m}^{2}$ and $18 \cdot 61 \mathrm{~m}^{2}$. Seed dispersal was very limited, especially relative to that of pollen, but the amount of long-distance seed dispersal in Primula vulgaris is unknown. Flowering plant density was difficult to measure in those populations which had a clumped distribution and low density, and different density estimates considerably influenced calculations of neighbourhood sizes, though neighbourhood areas were unaffected. Outcrossing rates were close to the expected value of 1 for four polymorphic loci in a single population of Primula vulgaris. Neighbourhood sizes in Primula vulgaris are sufficiently small for random genetic drift to be important in determining the genetic structure of populations and to have played a major role in the evolution of the species.
\end{abstract}

\section{INTRODUCTION}

Knowledge of effective population sizes makes it possible to assess the probable importance of random and non-random forces in the evolutionary history, present distribution and population structure of individual species. However, theoretical and practical problems of estimation mean that effective population sizes in plant species are largely unknown (Crawford, 1984). Attempts to estimate the size of local interbreeding groups in plant populations have usually been based on the neighbourhood, the area within a continuous array of organisms from which the parents of an individual at its centre may be treated as if drawn at random (Wright, 1946). When neighbourhoods (and, by implication, effective population sizes) are sufficiently small, differentiation may take place even within a continuum as the effect of dispersion is balanced by the tendency towards local fixation of alleles. This constitutes "isolationby-distance", which is itself an important component of the shifting balance theory of evolution (Wright, 1943; 1978). Differentiation can occur when neighbourhoods contain fewer than 200 individuals, and may be considerable when they have 20 or less; with neighbourhood numbers greater than 1000 there is virtual panmixia (Wright,

\footnotetext{
* Present address: Department of Forestry and Wood Science,
} University College of North Wales, Bangor, Gwynedd.
1946). Many of the published estimates of neighbourhood size are low, and indicate that random differentiation within plant populations may be considerable, in marked contrast to the pattern in animal species, where effective population sizes are often large enough for drift to be considered unimportant (Dobzhansky and Wright, 1943; Crumpacker and Williams, 1973; Barrowclough, 1980; Begon et al., 1980).

Neighbourhood studies have been carried out in populations of the common primrose, Primula vulgaris Huds., in North Wales, using Crawford's (1984) formulae to calculate neighbourhood areas and sizes from data on pollen and seed dispersal variances, outcrossing rate and density of flowering plants. Primula vulgaris is a heterostylous species with a sporophytic incompatibility system and an associated pollen dimorphism which can be used to study pollen flow in natural populations. Pin plants have tall, stigmas, short anthers and small pollen grains, while in thrums stigma and anther positions are reversed and the pollen grains are large. Self-compatible homostyles, which have tall stigmas and anthers, arise from crossing over within the "supergene" which controls the floral and incompatibility characteristics, and are found in populations of Primula vulgaris in South West England and the Chilterns.

Crosby $(1960 ; 1973)$ used a model of gene flow between small populations of 32-256 individuals 
to simulate the evolution and spread of homostyly in Primula vulgaris, with results that correspond closely to actual patterns of homostyle distribution in Somerset. Other models have considered the effect of population subdivision on the rate of spread and probability of fixation of an advantageous allele arising in the population (Levin and Kerster, 1975; Slatkin, 1976), and on the establishment and maintenance of patterns of allele frequencies (Rohlf and Schnell, 1971). Estimates of neighbourhood size provide empirical data for models of this kind, some of which can then be used to produce theoretical predictions of patterns of genetic variation which can be tested experimentally (Slatkin, 1980; 1981).

\section{MATERIALS AND METHODS}

\section{Pollen dispersal}

Eight populations of Primula vulgaris were included in a study of pollen movement in natural populations during the spring of 1981. At each site, a sample of one fully open flower from each of fifty plants was taken, the type of each plant (pin or thrum) recorded, and the distance of each plant from the nearest individual of the other morph (thrum or pin) measured. The stigma of each flower was removed, placed on a microscope slide in a drop of Sudan III, squashed gently and left for about 15 minutes. Slides were examined at $\times 400$ magnification and the number of foreign pollen grains (pin pollen on a thrum stigma or thrum pollen on a pin stigma) on the stigmatic surface was counted and recorded. For each population the number of foreign pollen grains found on the stigma of sampled plants was plotted as a function of the distances of those plants from the nearest plant of the opposite morph. The mean, variance and kurtosis of the distributions were calculated.

In a field experiment, 52 potted pin plants of Primula vulgaris were sunk into the ground in a square block, and two lines of potted thrum plants laid out on opposite sides of it. The experiment was set up in the second week of January 1981 and left until capsules could be seen to be developing in early June, when capsules were collected separately from each thrum plant, and the numbers of seed per capsule were recorded. Mean values per plant were plotted as a function of distance from the central block of pin plants, and the mean, variance and kurtosis of the distribution calculated.

\section{Seed dispersal}

A single population at a woodland site (Nantporth) was used in a study of seed movement carried out in July and August 1981. Circular pieces of cardboard $13 \mathrm{~cm}$ in diameter and covered with "Stikem Special" were pegged to the ground directly beneath ripening capsules and left until the capsules had released their seed. The distances from the centre of each cardboard circle to the centre of the appropriate capsule-bearing plant and the distances travelled by seed from the centre of the circle were measured. Two large cardboard circles $48 \mathrm{~cm}$ in diameter and covered with Stikem Special were used to encircle two plants with ripening capsules in the same population. After all seed had been released, the distances moved by the discharged seed from the centre of the plant were measured.

Two field experiments, one designed to study the dispersal of seeds and one to look at the distribution of seedlings around mother plants, were carried out from July 1982 until March 1983. In Experiment A, 51 potted Primula vulgaris plants bearing ripening capsules were sunk into the ground at $1 \mathrm{~m}$ square spacing and completely surrounded by fine nylon cloth with a mesh small enough to catch seeds as they were released from the capsules. In weekly inspections of the experiment the position of every released seed was marked with a waterproof pen, after which the seed was removed. The experiment was terminated in September 1982, when the distances moved by seeds from the centre of their maternal parents were measured. In Experiment B, 54 potted plants were sunk to ground level at $1 \mathrm{~m}$ square spacing and left undisturbed until mid-March 1983, by which time Primula vulgaris seedlings, even those at the cotyledon stage, could be readily identified. The positions of all seedlings and their maternal parents were then mapped.

\section{Flowering plant density}

Densities of flowering plants in eight natural populations of Primula vulgaris were measured in the spring of 1981. Counts were made of the total number of flowering individuals in the smallest possible rectangular area which included all the plants sampled in the pollen flow study.

In 1983, four populations (Nantporth, Penrhyn Castle, Plas Newydd and Treborth) were mapped by recording the coordinates of each flowering individual from reference posts of known position. The estimates of neighbourhood area (A) in table 
5 were used to calculate the radius of a circle of area $\mathrm{A}$ for each population, and circles of this radius were then drawn round a random sample of 50 plants on each population map. The number of individuals, other than the central plant, included in each circle was recorded, and the mean and variance of these "per plant density" (PPD) measurements calculated for each population. This method was suggested by R. Murray (personal communication) for use in populations showing clumped distributions of plants, where the use of a single average measure of density may be inappropriate. PPD estimates the average number of plants within the genetic neighbourhoods of individuals, and equals the overall average density of a population only when plants are regularly or randomly distributed within it.

\section{Outcrossing rate}

Families raised from seed collected from a woodland population at Penmon were used for the estimation of outcrossing rates. Thirty-nine families and ten seedlings per family were assayed for their genotypes at five polymorphic loci ( $A C P-1, A C P$ 2, $\alpha E S T-3, \beta E S T-6$ and $G D H)$, using the methods of Cahalan (1983).

Outcrossing rates were estimated by the method of Clegg et al., (1978), which uses a joint maximum likelihood procedure to estimate the outcrossing rate and allele frequency in the pollen parent from data on the numbers of heterozygous offspring of homozygous maternal parents. A multilocus estimate of outcrossing was also calculated using the method of Shaw et al., (1981).

\section{Neighbourhood area and size}

Neighbourhood area $(A)$ and size $\left(N_{e}\right)$ in each population were calculated from data on pollen $\left(\sigma_{p}^{2}\right)$ and seed $\left(\sigma_{s}^{2}\right)$ dispersal variances, outcrossing rate $(t)$ and density of flowering plants $(d)$, using Crawford's (1984) formulae. The required variances are the second moments of pollen and seed migration distance distributions transformed on to a single axis.

$$
A=4 \pi\left(\frac{t \sigma_{p}^{2}}{2}+\sigma_{s}^{2}\right)
$$

and

$$
N_{e}=4 \pi\left(\frac{t \sigma_{p}^{2}}{2}+\sigma_{s}^{2}\right) \frac{d}{2}(1+t) .
$$

Pollen and seed dispersal variances were both calculated around a zero mean, since there is no obvious directional dispersal of either seed or pollen in Primula vulgaris. An outcrossing rate of 1.0 and a seed dispersal variance of $1007.05 \mathrm{~mm}^{2}$ $\left(0.0010 \mathrm{~m}^{2}\right)$, estimated from the field experiment on seed dispersal (table 2), were initially used in calculating neighbourhood areas and sizes in all populations. The effect of using different parameter values was tested by calculating $A$ and $\mathrm{Ne}$ from the alternative estimates of $\sigma_{s}^{2}, d$ and $t$ (tables 2-4). All estimates were adjusted for the kurtosis of pollen distributions only, using the kurtosis/area relationship given by Crawford (1984).

\section{RESULTS}

\section{Pollen dispersal}

The mean distance, variance and kurtosis of pollen dispersal distribution in natural populations and the field experiment are given in table 1.

Table 1 Mean, variance and kurtosis of pollen distribution schedules in eight natural populations and one field

\begin{tabular}{|c|c|c|c|}
\hline Population & Mean $(\mathrm{m})$ & Variance & Kurtosis \\
\hline Treborth & $1 \cdot 52$ & $1 \cdot 305$ & $2 \cdot 08 \mathrm{NS}$ \\
\hline Penmon & $1 \cdot 48$ & $3 \cdot 254$ & $12 \cdot 39 * *$ \\
\hline Abraham's Bosom & $0 \cdot 84$ & $0 \cdot 225$ & $3 \cdot 26 \mathrm{NS}$ \\
\hline Nantporth & 0.92 & 0.944 & $19 \cdot 81^{* *}$ \\
\hline Rhoscefnir & 0.75 & $0 \cdot 170$ & $3 \cdot 47 \mathrm{NS}$ \\
\hline Talwrn & 0.63 & 0.113 & $36 \cdot 54^{* *}$ \\
\hline Penrhyn Castle & $1 \cdot 32$ & $1 \cdot 015$ & $5 \cdot 90^{*}$ \\
\hline Plas Newydd & 0.22 & 0.048 & $3 \cdot 58 \mathrm{NS}$ \\
\hline Field experiment & $2 \cdot 45$ & $1 \cdot 320$ & $1 \cdot 03 \mathrm{NS}$ \\
\hline
\end{tabular}
experiment of Primula vulgaris

$* P \leqq 0.05$. ** $P \leqq 0.01$. NS-Not significant $(P>0 \cdot 05)$.

\section{Seed dispersal}

The results of the seed dispersal studies in the natural population and the two field experiments are summarized in table 2 . Only those plants which produced more than thirty seeds or seedlings were included in the analysis of data from the field experiments, so that mean numbers of seeds or seedlings per maternal parent were higher than in the population study. The mean distances travelled by seeds or seedlings in the three studies were significantly different from each other at $P \leqq 0 \cdot 001$. 
Table 2 Seed dispersal in one natural population and one field experiment, and seedling distribution in one field experiment of Primula vulgaris

\begin{tabular}{lccr}
\hline & Natural population ${ }^{1}$ & Experiment $^{1}$ A & Experiment $^{2}$ B $^{2}$ \\
\hline No. plants & 22 & 27 & 25 \\
No. seeds/seedlings & 312 & 1787 & 1339 \\
Mean seeds/seedlings per plant & $14 \cdot 2$ & $66 \cdot 2$ & $53 \cdot 6$ \\
Mean distance (mm) & $37 \cdot 0^{* * *}$ & $72 \cdot 1 * * *$ & $98 \cdot 5^{* * *}$ \\
Variance & $700 \cdot 67$ & $1007 \cdot 05$ & $518 \cdot 22$ \\
\hline
\end{tabular}

' Seed dispersal.

${ }^{2}$ Seedling distribution.

*** Means significantly different at $P \leqq 0.001$.

\section{Flowering plant density}

1981 density counts, PPD values and the neighbourhood areas used in their calculation are given in table 3.

Table 3 Density of flowering plants, "per plant density" (PPD) and neighbourhood area $(A)$ in natural populations of Primula vulgaris

\begin{tabular}{lllll}
\hline Population & $\begin{array}{l}\text { Density } \\
\left.\text { (plants } / \mathrm{m}^{2}\right)\end{array}$ & $\begin{array}{l}A \\
\left(\mathrm{~m}^{2}\right)\end{array}$ & Mean & $\begin{array}{l}\text { PPD } \\
\text { Variance }\end{array}$ \\
\hline Treborth & $0 \cdot 12$ & $9 \cdot 24$ & 8.56 & 87.88 \\
Penmon & 0.54 & 18.61 & - & - \\
Abraham's Bosom & 1.45 & 1.45 & - & - \\
Nantporth & $2 \cdot 70$ & $5 \cdot 08$ & 2.66 & 7.86 \\
Rhoscefnir & 3.66 & 1.09 & - & - \\
Talwrn & $4 \cdot 75$ & 0.56 & - & - \\
Penrhyn Castle & $5 \cdot 30$ & 6.37 & 8.04 & 25.92 \\
Plas Newydd & 9.22 & 0.30 & 8.66 & 22.92
\end{tabular}

\section{Outcrossing rate}

Results for four of the five polymorphic loci are reported here, since it proved difficult to resolve bands at the ACP- 2 locus. Table 4 gives the four single locus estimates of the outcrossing rate, $t$, for the whole population sample and separately for pin and thrum maternal plants. The multilocus estimate of $t$ was 1.0915 and had a standard error of $0 \cdot 0529$.

Table 4 Single-locus estimates of outcrossing rate $(t)$ and their standard errors. Figures in brackets are the number of maternal plants in the population sample

\begin{tabular}{|c|c|c|c|c|c|c|}
\hline \multirow[b]{2}{*}{ Locus } & \multicolumn{2}{|c|}{ All plants (39) } & \multicolumn{2}{|c|}{ Pins (18) } & \multicolumn{2}{|c|}{ Thrums (16) } \\
\hline & $t$ & S.E. & $t$ & S.E. & $t$ & S.E. \\
\hline ACP-1 & $1 \cdot 0344$ & 0.0729 & $1 \cdot 1468$ & $0 \cdot 1049$ & 0.9011 & $0 \cdot 1265$ \\
\hline$\alpha$ EST- 3 & $1 \cdot 0525$ & 0.0762 & $1 \cdot 0121$ & 0.1162 & 1.0076 & 0.1142 \\
\hline$\beta$ EST- 6 & $1 \cdot 1004$ & 0.0742 & $1 \cdot 0504$ & $0 \cdot 1092$ & $1 \cdot 1012$ & 0.1162 \\
\hline $\mathrm{GDH}$ & 0.9029 & 0.0884 & $1 \cdot 2741$ & $0 \cdot 1320$ & $1 \cdot 1048$ & $0 \cdot 1154$ \\
\hline Mean & 1.0226 & 0.0782 & $1 \cdot 1209$ & $0 \cdot 1160$ & $1 \cdot 0064$ & $0 \cdot 1182$ \\
\hline
\end{tabular}

\section{Neighbourhood area and size}

Table 5 shows the range of neighbourhood areas and sizes obtained by using different values of $t$, $\sigma_{s}^{2}$ and $d$ for eight Primula vulgaris populations. Two sets of figures are given for those populations (Nantporth, Penrhyn Castle, Plas Newydd and Treborth) where "per plant density" measurements were made.

Table 5 Ranges of neighbourhood area $(A)$ and neighbourhood size $\left(N_{e}\right)$ in eight populations of Primula vulgaris, calculated from different estimates of dispersal variances, flowering plant density and outcrossing rate

\begin{tabular}{lcc}
\hline Population & $A\left(\mathrm{~m}^{2}\right)$ & $N_{\mathrm{v}}$ \\
\hline Treborth & $8 \cdot 14-9.93$ & 1 \\
& & $(66-89)^{*}$ \\
Penmon & $16 \cdot 43-20 \cdot 03$ & $8-11$ \\
Abraham's Bosom & $1 \cdot 27-1.56$ & 2 \\
Nantporth & $4 \cdot 48-5 \cdot 46$ & $12-15$ \\
& & $(11-15)^{*}$ \\
Rhoscefnir & $0 \cdot 96-1 \cdot 18$ & $3-4$ \\
Talwrn & $0 \cdot 53-0.60$ & $2-3$ \\
Penrhyn Castle & $5 \cdot 62-6.84$ & $28-38$ \\
& & $(43-58)^{*}$ \\
Plas Newydd & $0 \cdot 28-0 \cdot 34$ & $2-3$ \\
& & $(2-3)^{*}$ \\
\hline
\end{tabular}

* Ranges calculated using PPDs ("per plant densities").

\section{DISCUSSION}

Neighbourhood sizes $\left(N_{e}\right)$ in all eight populations of Primula vulgaris were low, ranging from 1 in the low density woodland population at Treborth to 38 in the open grassland population at Penrhyn Castle (table 5). Neighbourhood areas (A), which are expected to vary between populations depending on flowering plant density, ranged from $0.3 \mathrm{~m}^{2}$ in the high density array at Plas Newydd to $18.61 \mathrm{~m}^{2}$ at Penmon (table 4). Wright (1969) considers that in an area continuum of plants "appreciable" random genetic differentiation may occur when neighbourhood size is less than 200, and "much" differentiation when it is 20 or less. If the estimates reported here are accurate, the potential 
for random differentiation within populations of Primula vulgaris is great, and could be expected to lead to substructuring and local heterogeneity of allele frequencies. Estimates of outcrossing rates $(t)$ in such subdivided populations are biased downwards, with the effect being more pronounced with increased subdivision and with higher true values of $t$ (Ennos and Clegg, 1982). It is therefore surprising that the estimates obtained here were so consistently high. The families used in the estimation of outcrossing rate were taken from a population (Penmon) in a small woodland area which was regularly entered by cattle and horses, and it is possible that incidental seed dispersal by the animals was sufficient to overcome the effects of random genetic drift.

Table 5 shows the effect of using the different measured values of seed dispersal variance, outcrossing rate and density in the calculation of neighbourhood size and area. Only changes in density had any marked effect on the estimates, with the result that neighbourhood areas in each population had a very small range but values of $N_{e}$ in two of the four populations for which both methods of density estimation were used were very different, with a 2 -fold increase in the estimate of $N_{e}$ for Penrhyn Castle and a remarkable increase from 1 to a range of $66-89$ for Treborth. The population at Treborth had the lowest overall density of all those surveyed (table 3 ), and contained small groups of only moderate density separated by areas where Primula vulgaris was absent. Despite this, the variance of pollen dispersal distances was relatively high (table 1), suggesting that at least some pollen was travelling the distances separating groups of plants. Pollinators may modify their usual pattern of behaviour in low density arrays by flying longer distances than foraging theory predicts, in which case a reighbourhood size estimate of 1 seems low and one of 66-89 less improbable.

Neighbourhood size is comparable to deme size in species which have an even distribution pattern (Hartl, 1980), but many populations, including some of those included in this study, depart from this ideal. Wright (1969) suggests that in species growing in randomly distributed clusters of high density with little dispersal between clusters, neighbourhood sizes will be larger than numbers of individuals in localised, high density clumps, but this prediction is not rigorously tested by any of the populations here. Use of a measure of "per plant density" to overcome some of the difficulties of density estimation was not wholly satisfactory, though it did illustrate the problems associated with irregular distribution patterns, particularly in low density populations. The question of flowering plant density and its relationship to neighbourhood estimates needs to be further investigated, both empirically and theoretically.

The values of $A$ and $N_{e}$ reported here are at the low end of the range found in other plant species (Kerster and Levin, 1968; Levin and Kerster, 1968; 1969; Richards and Ibrahim, 1978; Schaal and Levin, 1978; Beattie and Culver, 1979; Schaal, 1980; Schmitt, 1980; Saeed, 1984), but are consistent with the observation that neighbourhood sizes in plant populations are often small, and that effective population sizes may be even smaller. Factors which have not always been taken into account in neighbourhood studies, but which would reduce effective numbers below published estimates, include kurtosis of pollen and seed dispersal distributions, selfing, variation in fecundity and density estimates based on standing crop and not on breeding individuals (Crawford, 1984). Allowance has been made here for both kurtosis and selfing, but the importance of differential fecundities in populations of Primula vulgaris is unknown, and the problems of density estimation have been discussed. Neither factor is expected to have much effect on neighbourhood areas, but might reduce effective population numbers within those areas, implying that the values of $N_{e}$ in table 5 could be overestimates. However, Wright's method of estimation is unreliable for small neighbourhood sizes, and this inaccuracy is probably more important than any influences tending to inflate the values in table 5 .

There are reasons for suspecting that gene flow, the factor which determines the level of subdivision within a continuous population of individuals, has actually been underestimated in this study, as it has in a number of others (Levin, 1981). It is known that pollen dispersal data underestimates pollenmediated gene flow in Primula vulgaris (Cahalan, 1983). In addition, the data on seed dispersal provided no information on long-distance transport of seed by mice or other small mammals, although isolated plants of Primula vulgaris can be found growing in places where it seems unlikely that they have been planted by humans, implying that longdistance transport of seed does sometimes occur.

Gene flow between neighbourhoods is independent of neighbourhood area, and the amount of genetic divergence between two points in a population depends on the number of neighbourhoods between them, not on their absolute separation. Random local differentiation becomes a major determinant of the genetic structure of 
populations when neighbourhoods are small compared with the environmental patches over which selection acts uniformly. Underestimates of gene flow in plant populations lead to underestimates of neighbourhood sizes and areas, with the consequences that there is less random differentiation and isolation-by-distance and that stronger selection is needed to maintain local selective differentiation than would be expected from neighbourhood statistics based on dispersal data (Levin, 1981).

The values of $A$ and $N_{e}$ in table 5 may be too low by some 20 per cent (Cahalan, 1983), which increases the range of neighbourhood areas to $0 \cdot 33-24 \mathrm{~m}^{2}$ and that of neighbourhood sizes to 1-42 plants. These are still small enough for appreciable random genetic differentiation within local populations, and random forces probably exert a major influence on present population structures in Primula vulgaris. Historically, neighbourhood sizes may not always have been as small as they are today if the original pollinator of the species has become extinct (Woodell, 1960), so that pollen dispersal is much more limited than it once was. It is also possible that neighbourhood sizes increase in warmer parts of the species' range, where insect activity is greater, pollination more efficient and seeds are carried further by ants or other agents. The effects of such temporal and spatial variation can only be a matter for speculation; in the absence of evidence to the contrary it is suggested that random processes have also been important in the evolution of Primula vulgaris.

Acknowledgments We wish to thank MrChris Whitaker of the Statistical Advisory Unit at UCNW, the staff of the University field station at Pen y Ffridd and Jack Crosby, primrose expert. Also, The National Trust and the North Wales Naturalists' Trust for allowing field work to be carried out on their land. CC was in receipt of a University of Wales studentship.

\section{REFERENCES}

BARROWCLOUGH, G. F. 1980. Gene flow, effective population sizes and genetic variance components in birds. Evolution, 34, 789-798.

BEATTIE, A. J. AND CUIVER, I. C. 1979. Neighbourhood size in Viola. Evolution, 33, 1226-1229.

BFGON, M., KRIMBAS, ( B. AND LOUKAS, M. 1980. The genetics of Drosophila subobscura populations. XV. Effective size of a natural population estimated by three independent methods. Heredity, 45, 335-350.

CAHALAN, C. M. 1983. Neighbourhood size and population structure in Primula vulgaris Huds. Ph.D. thesis, University of Wales.

CLEGG, M. T., KAHL.F. R, A. L. AND ALLARD, R. W. 1978. Estimation of the life cycle components of selection in an experimental plant population. Genetics, 89, 765-792.
CRAWFORI, T. J. 1984. What is a population? Shorrocks, B. (ed.): Evolutionary Ecology, Blackwell Scientific Publications, Oxford, pp. 135-173.

CROSBY, J. L. 1960. The use of electronic computation in the study of random fluctuations in rapidly evolving populations. Phil. Trans. Roy. Soc. B. 242, 551-573.

CROSBY, J. L. 1973. Computer simulation in genetics. John Wiley and Sons.

CRUMPACKER, D. W. AND Williams, J. S. 1973. Density, dispersion and population structure in Drosophila pseudoobscura. Ecol. Monographs, 43, 499-538.

DOBZHANSKY, T. AND WRIGHT, S. 1943. Genetics of natural populations. X. Dispersion rates in Drosophila pseudoobscura. Genetics, 28, 304-340.

ENNOS, R. A. AND CLEGG, M. T. 1982. Effect of population substructuring on estimates of outcrossing rate in plant populations. Heredity, 48, 283-292.

HARTL, D. L. 1980. Principles of population genetics. Sinauer Associates Inc.

KERSTER, H. W. ANI) LEVIN, D. A. 1968. Neighbourhood size in Lithospermum caroliniense. Genetics, 60, 577-587.

LEVIN, D. A. 1981. Dispersal versus gene flow in plants. Ann. Miss. Bot. Gard., 68, 233-253.

LEVIN, D. A. AND KERSTER, H. W. 1968. Local gene dispersal in Phlox. Evolution, 22, 130-139.

L.EVIN, D. A. AND KERSTER, H. W. 1969. Density-dependent gene dispersal in Liatris. Amer. Nat., 103, 61-74.

LEVIN, D. A. AND KERSTER, H. W. 1975. The effect of gene dispersal on the dynamics and statistics of gene substitution in plants. Heredity, 35, 317-336.

RICHARDS, A. J. AND IBRAHIM, H. 1978. Estimation of neighbourhood size in two populations of Primula veris. In: The pollination of flowers by insects. Ed. A. J. Richards. Linnean Soc. Symp. Series, 6, 165-174.

ROHLF, F. J. AND SCHNELL, G. D. 1971. An investigation of the isolation-by-distance model. Amer. Nat., 105, 295-324.

SAEED, M. 1984. The effects of breeding system on genetic variation in Vicia species. Ph.D. thesis, University of Wales.

SCHAAL, B. A. 1980. Measurement of gene flow in Lupinus texensis. Nature, 284, 450-451.

SCHAAL, B. A. ANI LEVIN, D. A. 1978. Morphological differentiation and neighbourhood size in Lialris cylindracea. Amer. J. Bot., 65, 923-928.

SCHMITT, J. 1980. Pollinator foraging behaviour and gene dispersal in Senecio (Compositae). Evolution, 34, 934-943.

SHAW, D. V., KAHLER, A. L. AND ALLARD, R. W. 1981. A multilocus estimator of mating system parameters in plant populations. Proc. Nat. Acad. Sci., 78, 1298-1302.

SI.ATKIN, M. 1976. The rate of spread of an advantageous allele in a subdivided population. In: Population genetics and ecology. Ed. S. Karlin and E. Nevo. Academic Press. pp. $767-780$

SLATKIN, M. 1980. The distribution of mutant alleles in a subdivided population. Genetics, 95, 503-523.

SLATKIN, M. 1981. Estimating levels of gene flow in natural populations. Genetics, 99, 323-335.

WOODELL, S. R. J. 1960. What pollinates primulas? New Scientist, 8, 568-571.

WRIGHT, S. 1943. Isolation by distance. Genetics, 28, 114138.

WRIGHT, S. 1946. Isolation by distance under diverse systems of mating. Genetics, 3l, 39-59.

WRIG;HT, S. 1969. Evolution and the genetics of populations. Vol. 2. The theory of gene frequencies. University of Chicago Press.

WRICjHT, S. 1978. Evolution and the genetics of populations. Vol. 4. Variability within and among natural populations. University of Chicago Press. 